\title{
Process limits for percussion drilling of stainless steel with ultrashort laser pulses at high average powers
}

\author{
David Brinkmeier ${ }^{1,2}\left(\right.$ D . Daniel Holder ${ }^{1} \cdot$ André Loescher $^{1} \cdot$ Christoph Röcker $^{1} \cdot$ Daniel J. Förster $^{1,3} \cdot$ Volkher Onuseit $^{1}$. \\ Rudolf Weber $^{1}$ - Marwan Abdou Ahmed ${ }^{1}$. Thomas Graf ${ }^{1,2}$
}

Received: 16 September 2021 / Accepted: 28 November 2021 / Published online: 13 December 2021

(c) The Author(s) 2021

\begin{abstract}
The availability of commercial ultrafast lasers reaching into the $\mathrm{kW}$ power level offers promising potential for high-volume manufacturing applications. Exploiting the available average power is challenging due to process limits imposed by particle shielding, ambient atmosphere breakdown, and heat accumulation effects. We experimentally confirm the validity of a simple thermal model, which can be used for the estimation of a critical heat accumulation threshold for percussion drilling of AISI 304 steel. The limits are summarized in a processing map, which provides selection criteria for process parameters and suitable lasers. The results emphasize the need for process parallelization.
\end{abstract}

Keywords Percussion drilling $\cdot$ Metals $\cdot$ Ultrashort laser pulses $\cdot$ Heat accumulation

\section{Introduction}

The trade-off between quality and productivity (in terms of processed material volume or mass per unit of time or energy) is a major challenge in laser material processing, especially with ultra-short pulses. The rapid developments of ultrafast lasers documented in Fig. 1 show that lasers with average powers in the order of $\mathrm{kW}$ have recently transitioned from scientific to commercial availability, and multi-kW commercial lasers can be expected within a decade.

These $\mathrm{kW}$ class ultrafast lasers mark a paradigm shift for materials processing: Based on simple energetic considerations these lasers enable the departure from niche applications of micro materials processing to high volume manufacturing applications [71-73].

However, especially in spatially concentrated processes such as drilling, the promise of "cold ablation", i.e.

David Brinkmeier

david.brinkmeier@ifsw.uni-stuttgart.de

1 Institut Für Strahlwerkzeuge (IFSW), University of Stuttgart, Pfaffenwaldring 43, 70569 Stuttgart, Germany

2 Graduate School of Advanced Manufacturing Engineering (GSaME), University of Stuttgart, Nobelstrasse 12, 70569 Stuttgart, Germany

3 LightPulse Laser Precision, Pfaffenwaldring 43, 70569 Stuttgart, Germany processing without significant thermal effects (defects) in the remaining adjacent material, can no longer be met. Heat accumulation [74] effects during pulsed drilling [75-79], scanning $[72,75,79,80]$, and burst processing [81] in many cases represent the primary effect leading to damage or degradation of the surface quality next to the processing area.

In the literature, heat accumulation in pulsed laser processing is approached with varying degrees of accuracy regarding the modelling of the underlying physical effects, ranging from full numerical modelling that allows for the consideration of effects such as electron-ion temperature relaxation [82] and phase transitions, semi numerical methods [72, 80] based on analytical solutions [83] to the heat equation, sometimes extended to more complex geometries of the heat sources [80], to phenomenological models which lend themselves to analytical treatment $[75,76,79]$.

Another limiting aspect is atmosphere breakdown or ionization of the ambient atmosphere, which can lead to absorption of the incident laser radiation prior to reaching the target, and also leads to distortion of the beam profile as well as self-focusing [84-89]. Atmosphere breakdown can lead to a reduction of the process efficiency due to the attenuation of the beam prior to reaching the target, degraded surface quality due to distortions of the beam profile, and reduced reproducibility because of the random nature of the wavefront distortions. 


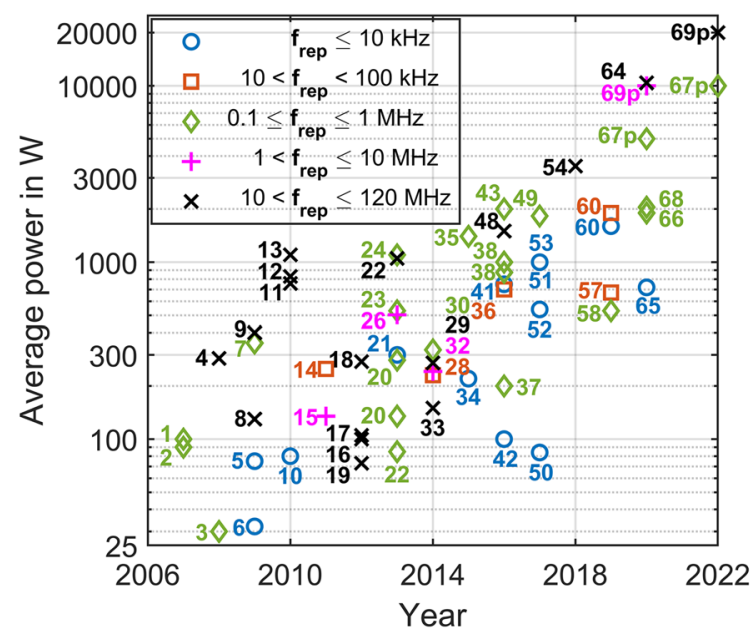

Fig. 1 Scientific (left) and industrial (right) ultrafast lasers [1-70] with pulse durations $<15 \mathrm{ps}$ and pulse repetition rates $f_{\text {rep }}<120 \mathrm{MHz}$. Index "p" denotes systems in development. The numbers next to the

The primary effect is the interaction of the laser pulse with the ionized ambient atmosphere generated by the laser pulse itself, which is why for sub 100 fs pulses the effective energy loss is often negligible, as the ionization occurs later during the pulse [86]. While the threshold depends on various factors such as the composition of the ambient atmosphere [89-94], pulse duration [84, 95, 96], wavelength [97, 98], pressure [98, 99], and focal volume $[91,95,100]$, an often cited threshold value for picosecond pulses in the near infrared in air is $2 \times 10^{13} \mathrm{~W} / \mathrm{cm}^{2}$ $[84,95,100,101]$. The use of inert gases [89-94] and lower ambient pressures $[89,91-94,98,99]$ can shift the threshold by roughly one order of magnitude, however, atmosphere breakdown presents an upper limit for usable power densities, and hence the irradiated pulse energy, for a given setup.

Yet another documented effect is particle shielding, or absorption in residual ablation plasma, which refers to the interaction of laser pulses with ablated matter. Similar to atmosphere ionization this effect limits the economically usable range of laser parameters due to attenuation and distortions of the beam. The key difference to the effect of atmosphere breakdown is the lifecycle and density of the particle cloud, which can affect the absorption of subsequent pulses for up to several microseconds $[85,86,102]$.

Particle shielding has also been suggested to depend "on ablation pulse fluence, target material and further process parameters like the geometry of the ablation spot/hole" [102], the latter of which has been investigated experimentally for the case of percussion drilling in silicon by Döring et al. [103]. The experimental determination of a threshold is challenging, because particle shielding is seldom an isolated effect as an increase of the pulse repetition rate for otherwise constant

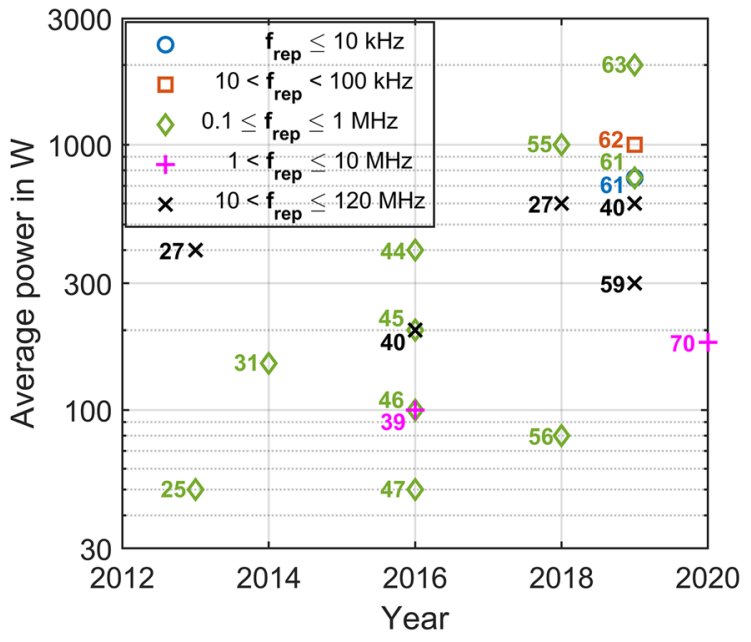

markers refer to the associated references. The lasers are divided into different pulse repetition ranges to distinguish between high repetition and high energy lasers

parameters also increases the average irradiated power, and therefore heat accumulation effects [77].

For the case of percussion drilling in stainless steel at a wavelength of $1030 \mathrm{~nm}$ and pulse duration of $800 \mathrm{fs}$, Ancona et al. $[76,104]$ reported a noticeable impact of particle shielding effects for a pulse repetition rate of $500 \mathrm{kHz}$ for low fluencies and pulse energies below $70 \mu \mathrm{J}$, whereas a threshold of $200 \mathrm{kHz}$ has been noted for pulse energies beyond that value.

This paper focuses on the experimental validation (Sect. 3) of a simple thermal model for the consideration of heat accumulation effects in percussion drilling. The limits of heat accumulation are combined with known thresholds for atmosphere breakdown and particle shielding, and with an estimation for the achievable depth of the borehole to derive a process windows graph for the percussion drilling of stainless steel.

\section{Process limits}

Based on a model for a pulsed laser-induced thermal process assuming repetitive heat inputs by a point source in a half infinite body and a three dimensional heat flow, it was shown that the temperature at the time immediately before the incidence of the $\left(N_{P}+1\right)$ th laser pulse is given by [75]

$T\left(N_{\mathrm{P}}\right)=T_{0}+\frac{2 \eta_{\mathrm{res}} E_{\mathrm{p}} f_{\text {rep }}^{\frac{3}{2}}}{\rho c_{\mathrm{p}}(4 \pi \kappa)^{\frac{3}{2}}} \sum_{N=1}^{N_{\mathrm{p}}} \frac{1}{N^{\frac{3}{2}}}$,

where $\kappa$ is the thermal diffusivity, $T_{0}$ the ambient temperature, $E_{\mathrm{p}}$ the pulse energy, $f_{\text {rep }}$ the pulse repetition rate, $\rho$ the mass density of the material, $c_{\mathrm{p}}$ its specific heat capacity, and $\eta_{\text {res }}$ is the fraction of the pulse energy that remains in the 
non-ablated material next to the interaction zone and leads to the considered increase of the temperature.

Assuming that there is a critical temperature $T_{\text {crit }}$ (such as the melting temperature of the processed material) which should not be exceeded at the moment of the incidence of a pulse, i.e. $T\left(N_{\mathrm{P}}\right) \leq T_{\text {crit }}$, to avoid quality issues, Eq. (1) implies that either only a limited number of pulses $N_{\mathrm{P}}$ can be applied or that the pulse energy $E_{\mathrm{p}}$ and/or the repetition rate $f_{\text {rep }}$ should be so small, that $T\left(N_{\mathrm{P}}\right)$ does not exceed $T_{\text {crit }}$ even for $N_{\mathrm{P}} \rightarrow \infty$. This may be analyzed by considering the convergence behavior of the sum

$C_{N_{\mathrm{p}}}=\sum_{N=1}^{N_{\mathrm{p}}} \frac{1}{N^{\frac{3}{2}}}$

in Eq. (1). For an infinite number of pulses $N_{\mathrm{p}} \rightarrow \infty, C_{N_{\mathrm{p}}}$ converges to 2.61. However, after only ten pulses $C_{N_{\mathrm{p}}}$ already amounts to 2.0. Assuming that in the majority of percussion drilling processes anywhere in between ten and an infinite number of pulses are applied, $C_{10}=2$ and $C_{\infty}=2.61$ may be used to evaluate Eq. (1), which then define the upper- and lower thermal boundaries for percussion drilling processes, respectively.

By setting $T\left(N_{\mathrm{P}}\right)=T_{\text {crit }}$, and solving Eq. (1) for the pulse repetition rate one finds that with a given pulse energy and a given number of pulses the repetition rate is limited to

$f_{\text {rep,crit }}=4 \pi \kappa \times\left(\frac{\left(T_{\text {crit }}-T_{0}\right) \rho c_{\mathrm{p}}}{2 \eta_{\text {res }} C_{N_{\mathrm{p}}}}\right)^{\frac{2}{3}} \times E_{p}^{-\frac{2}{3}}$.

Expressing the limit imposed by heat accumulation in this form is motivated by the observation that both the pulse energy $E_{\mathrm{p}}$ and the number of applied pulses is not a freely selectable parameter in percussion drilling: A minimum number of pulses as well as a minimum pulse energy is required to reach a given drilling depth.

In fact, with a given diameter $d$ of a Gaussian beam on the workpiece, the absorbed fluence and thus the pulse energy is the primary parameter defining the achievable maximum depth [105]. The maximum achievable borehole depth $z_{\max }$ may be determined as the steady-state condition of the iterative model presented in [105], in which case the drilling progress is assumed to cease when the absorbed fluence on the borehole wall is equal to the material-specific threshold $\phi_{\mathrm{A}, \mathrm{th}}$ for the absorbed fluence everywhere within the hole. Expressed in terms of the absorbed peak fluence on the beam axis at normal incidence $\phi_{0 \text {,abs }}=8 A E_{\mathrm{p}} /\left(\pi d^{2}\right)$, where $A$ is the absorptivity at normal incidence, the achievable depth $z_{\max }$ is found to be $z_{\max }=d \times \sqrt{\frac{\left(\frac{\eta_{A}}{A} \times \phi_{0, \text { abs }}\right)^{2} \times\left(1-\frac{\phi_{A, \text { th }}}{\phi_{0, \text { abs }}}\right)^{2}-\phi_{\mathrm{A}, \mathrm{th}}^{2} \times \ln ^{2}\left(\frac{\phi_{0, \mathrm{abs}}}{\phi_{\mathrm{A}, \mathrm{h}}}\right)^{2}}{8 \times \phi_{\mathrm{A}, \mathrm{th}}^{2} \times \ln \left(\frac{\phi_{0, \mathrm{abs}}}{\phi_{\mathrm{A}, \mathrm{h}}}\right)}}$,

where $\eta_{A}$ is the overall absorptance of the radiation inside the borehole introduced by Gouffe [106, 107], with corrections by Hügel and Graf [108], as summarized in Ref. [105].

As a minor amendment to the expression given in Ref. [105], Eq. (4) additionally includes the factor $1-\phi_{\mathrm{A}, \mathrm{th}} / \phi_{0, \mathrm{abs}}$, which takes into account that the energy irradiated outside the ablation entrance of the hole with the radius $r_{\text {abl }}=d / 2 \times \sqrt{0.5 \times \ln \left(\phi_{0, \text { abs }} / \phi_{\mathrm{A}, \mathrm{th}}\right)}[105]$ is not distributed inside the borehole. Hence, the energy $Q_{\text {hole }}$ contributing to the drilling process is less than the pulse energy $E_{\mathrm{p}}$ and given by

$Q_{\text {hole }}=\int_{0}^{r_{\text {abl }}} \int_{0}^{2 \pi} \frac{2 E_{\mathrm{p}}}{\pi w} \times e^{-2\left(\frac{r}{w}\right)^{2}} \operatorname{rdrd} \varphi=E_{\mathrm{p}}\left(1-\frac{\phi_{\mathrm{A}, \mathrm{th}}}{\phi_{0, \mathrm{abs}}}\right)$,

where $w=d / 2$ is the radius of the Gaussian beam and $\phi_{0, \text { abs }} \geq \phi_{\mathrm{A}, \mathrm{th}}$.

It is worth noting that $Q_{\text {hole }}$ converges to $E_{\mathrm{p}}$ for $\phi_{0, \text { abs }} \gg \phi_{\mathrm{A}, \mathrm{th}}$, which at the same time is the requirement for drilling of deep holes with high aspect-ratios according to Eq. (4). To enable an explicit estimation of $z_{\max }$ one may assume $\eta_{\mathrm{A}} \approx 1$ for high aspect-ratio boreholes.

Since $\eta_{\mathrm{A}}$ depends on the geometry of the borehole the iterative approach [105] must be employed to solve Eq. (4) for shallow holes with $\eta_{\mathrm{A}} \ll 1$. As the main focus is on the limit imposed when drilling holes with high aspect-ratios, the approximation $\eta_{\mathrm{A}} \approx 1$ is used here.

The process windows for percussion drilling are discussed in the following using the example of drilling of cold-rolled stainless steel of the type AISI 304 with picosecond lasers with a wavelength of $1030 \mathrm{~nm}$ using a circularly polarized beam. The material specific parameters are adopted from [75, 105], and summarized in Table 1.

Inserting these values in Eq. (3), assuming applied pulses $N_{\mathrm{P}}$ between ten $\left(C_{10}=2\right)$ and infinity $\left(C_{\infty}=2.61\right)$, yields the limit imposed by heat accumulation as shown by the correspondingly labelled red band in Fig. 2.

Hence the heat accumulation limit is represented as the region within which the limit for percussion drilling with ten (upper edge of the band) or more pulses is expected. The limit for an infinite number of pulses corresponds to the lower edge of the red band. The fact that this band is very narrow and almost shrinks to a line in the representation of Fig. 2 points out that the heat accumulation limit is a hard boundary for practically all conceivable percussion drilling processes, i.e. all processes that require more than ten consecutive pulses. 
Table 1 Material properties of CrNi-steel (AISI 304)

\begin{tabular}{lll}
\hline Property & Value & Unit \\
\hline Thermal diffusivity $\kappa$ & $0.4 \times 10^{-5}$ & $\mathrm{~m} / \mathrm{s}$ \\
Density $\rho$ & 7900 & $\mathrm{~kg} / \mathrm{m}^{3}$ \\
Heat capacity $c_{\mathrm{p}}$ & 477 & $\mathrm{~J} /(\mathrm{kg} \mathrm{K})$ \\
Absorptivity at normal incidence $A$ & 0.38 & \\
Melting/critical temperature $T_{\text {crit }}$ & 1500 & ${ }^{\circ} \mathrm{C}$ \\
Ambient temperature $T_{0}$ & 20 & ${ }^{\circ} \mathrm{C}$ \\
Residual heat $\eta_{\text {res }}$ & 12.5 & $\%$ \\
Threshold fluence $\phi_{\mathrm{A}, \mathrm{th}}$ & 0.12 & $\mathrm{~J} / \mathrm{cm}^{2}$ \\
Designation per EN 10027 & X5CrNi18-10 & \\
\hline
\end{tabular}

From Opt. Express 22, 11312 [75] and Appl. Phys. A 127, 1 [105]

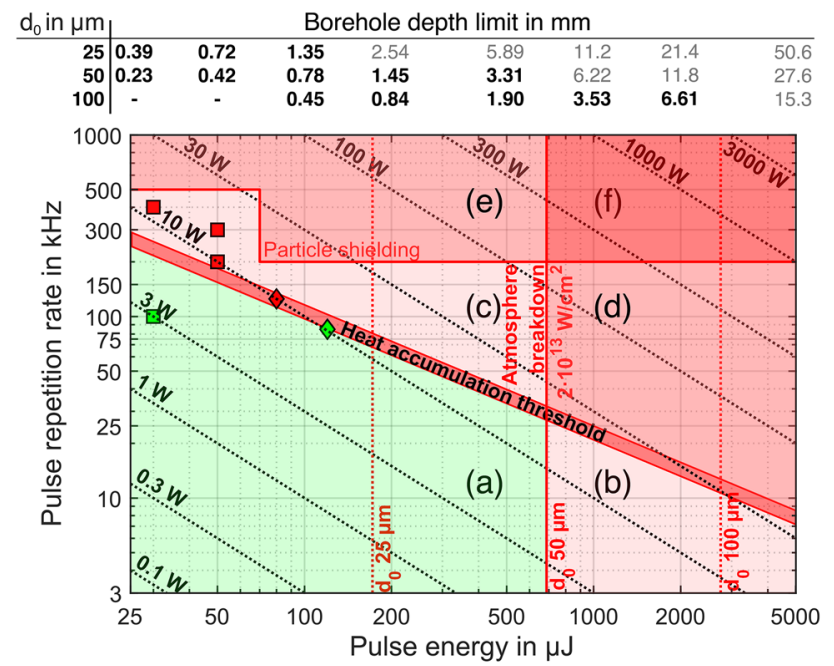

Fig. 2 Process limits for percussion drilling in AISI 304. The heat accumulation threshold is given by a narrow band, resulting from Eq. (3) using $C_{10}=2.0$ (upper edge of the band) and $C_{\infty}=2.61$ (lower edge of the band), and the parameters in Table 1. The atmosphere breakdown threshold assumes a pulse duration of 7 ps (Gaussian in space and time) and a beam diameter $d_{0}=50 \mu \mathrm{m}(25 \mu \mathrm{m} / 100 \mu \mathrm{m})$ for the solid (dashed) line(s). The borehole depth limit and threshold pulse energy is presented for three beam diameters $d_{0}$ in order to highlight the impact of the irradiated fluence on the achievable borehole depth, and values shaded grey indicate processing at peak intensities beyond the atmosphere breakdown threshold. The values for $d_{0}=100 \mu \mathrm{m}$ and the pulse energies of 25 and $50 \mu \mathrm{J}$ are omitted as the small aspect ratios are not consistent with the approximation $\eta_{A} \approx 1$. Diagonal dotted lines represent isolines of constant power, representing all possible pulsed laser sources providing that average power. Squares and diamonds are experimental results from Ancona et al. [76, 104] and Weber et al. [75], where green and red represents unnoticeable and excessive heat accumulation, respectively.

The threshold values for the effect of particle shielding were adopted from the experiments conducted by Ancona et al. [76, 104], and the borehole depth limit given by Eq. (4) is evaluated for a beam diameter of $25 \mu \mathrm{m}, 50 \mu \mathrm{m}$ and $100 \mu \mathrm{m}$. In order to avoid ambient air breakdown, the threshold pulse energy $E_{\mathrm{p}, \mathrm{th}}$ which should not be exceeded in a spatio-temporal Gaussian beam, whose peak intensity is four times the mean value, is given by

$E_{\mathrm{p}, \mathrm{th}}=\frac{I_{\mathrm{th}} \tau_{\mathrm{p}} \pi d^{2}}{16}$.

The corresponding limits shown in Fig. 2 result from the assumption of a pulse duration $\tau_{\mathrm{p}}$ of $7 \mathrm{ps}$, and the threshold intensity $I_{\text {th }}=2 \times 10^{13} \mathrm{~W} / \mathrm{cm}^{2}$ as mentioned in the introduction.

Six distinct regions can be identified in Fig. 2:

(a) Accessible for percussion drilling without excessive heat accumulation, particle shielding, or atmosphere breakdown.

(b) Expected to yield adverse effects due to atmosphere breakdown.

(c) Expected to yield unacceptable heat accumulation effects.

(d) Combines the issues of (b) and (c).

(e) In addition to excessive heat accumulation, particle shielding comes into play at pulse repetition rates beyond several hundred $\mathrm{kHz}$.

(f) Expected to combine particle shielding, excessive heat accumulation, and atmosphere ionization.

Experimental results taken from Weber et al. [75] and Ancona et al. [76, 104] have been added to Fig. 2 as a first confirmation of these limits. Experiments where no detrimental effects were observed are shown with the green data points, the ones that suffered from heat accumulation effects are shown in red.

The beam diameters and processing strategies in the cited experiments vary: The experiments reported on in Weber et al. [75] were conducted with a beam diameter of $20 \mu \mathrm{m}$ and the processing strategy was helical drilling with a drilling radius of $40 \mu \mathrm{m}$, while the process conditions of Ancona et al. were percussion drilling with a beam diameter of $17 \mu \mathrm{m}$ [104] and $50 \mu \mathrm{m}$ [76]. The rationale for not having to take these differences into account in Fig. 2 is the consideration that in either case the energy is irradiated into an area so small, that Eq. (3) accurately models the thermal limit for all cited cases.

In order to verify the latter, and whether the heat accumulation limit per Eq. (3) yields a usable estimation for the occurrence of excessive heat accumulation, experiments over a representative parameter set in region a) and c) of Fig. 2 were carried out as described in the following. To also confirm the assumption that the influence of the beam diameter on heat accumulation is negligible in common configurations, the experiments were repeated for 
different beam diameters under otherwise identical process conditions.

\section{Experiments}

The laser used is the successor to the scientific system described in [35]. The wavelength of the laser is $1030 \mathrm{~nm}$, the beam quality factor $M^{2}<1.3$, and the pulse duration $\tau_{\mathrm{p}}=7 \mathrm{ps}$ (Gaussian). A maximum average incident power of $570 \mathrm{~W}(1.9 \mathrm{~mJ}$ at $300 \mathrm{kHz})$, as measured on the work piece, was applied.

Percussion drilling experiments were conducted on polished $5 \mathrm{~mm}$ thick rectangular $(30 \times 30 \mathrm{~mm})$ samples of AISI 304 stainless steel (cf. Table 1 ) using a circularly polarized beam. Adjacent boreholes were laterally separated by $2 \mathrm{~mm}$ in either direction. The irradiated pulse energies ranged from $25 \mu \mathrm{J}$ to $1900 \mu \mathrm{J}$, the repetition rates from 3 to $300 \mathrm{kHz}$, and the number of consecutively applied pulses from 10 to $10^{6}$. A total of 1100 sets of process parameters were applied using two different focusing lenses with focal lengths of $162 \mathrm{~mm}$ and $340 \mathrm{~mm}$.

The two resulting beam diameters on the workpiece were determined to be $60 \mu \mathrm{m}$ and $107 \mu \mathrm{m}$ using Liu's method [109] under process conditions. Hence the fluence was higher by a factor of 3.18 with the tighter focusing. The parameter variations for pulse energy and number of pulses were performed at a constant pulse repetition rate and repeated for the different pulse repetition rates. Successive process parameters were performed with a constant number of pulses and with successively increased pulse energy. When excessive melt was generated at a given pulse energy, otherwise identical processing parameters exceeding that pulse energy were skipped to protect the optical components. Sufficient time was awarded between the individual drillings on the same sample to ensure sample temperatures close to ambient temperature $T_{0}=20^{\circ} \mathrm{C}$. An excerpt from the dataset [110] is presented in Fig. 3, showing an overview of the experiments with pulse repetition rates of 3 and $300 \mathrm{kHz}$.

The entrances of the drilled boreholes were inspected using a digital microscope at $10 \times$ magnification. Traces of smoke on the surface, as well as discoloration resulting from residual cleaning agent, are not an indicator for heat accumulation and are easily distinguishable from the generated melt on the micrographic pictures by the naked eye. With a repetition rate of $300 \mathrm{kHz}$ significant amounts of molten material are observed for most of the parameter sets, even leading to sealed borehole entrances.

The classification on whether a given combination of pulse repetition rate and pulse energy leads to heat accumulation or not is illustrated at the example of Fig. 4 which shows the results obtained with a pulse energy of $625 \mu \mathrm{J}$.

With a given pulse energy, several holes with different number of pulses $N_{\mathrm{P}} \geq 10$ (abscissa) were drilled with different repetition rates (ordinate). The parameter combination of pulse energy and repetition rate (individual rows in Fig. 4) was classified as good (green), intermediate (yellow), or poor (red) when less than one third, one third to one half, or more than half of the holes are affected by significant amounts of molten material, respectively.

The classification results are summarized in Fig. 5.

Regardless of the two applied beam diameters, the results are in good agreement with the theoretical expectations. Together with the previous results from Weber et al. [75] and Ancona et al. [76, 104] this indicates that the description of the heat accumulation limit per Eq. (3) is suitable for typical process conditions of laser drilling with ultrashort pulses, despite the simplified assumptions of the used heat accumulation model.
Fig. 3 Entrances of the boreholes were drilled with a pulse repetition rate of $3 \mathrm{kHz}$ (left), $300 \mathrm{kHz}$ (right), and a beam diameter of $60 \mu \mathrm{m}$. Blank images represent skipped parameters. The edge length of the individual square images is $1 \mathrm{~mm}$
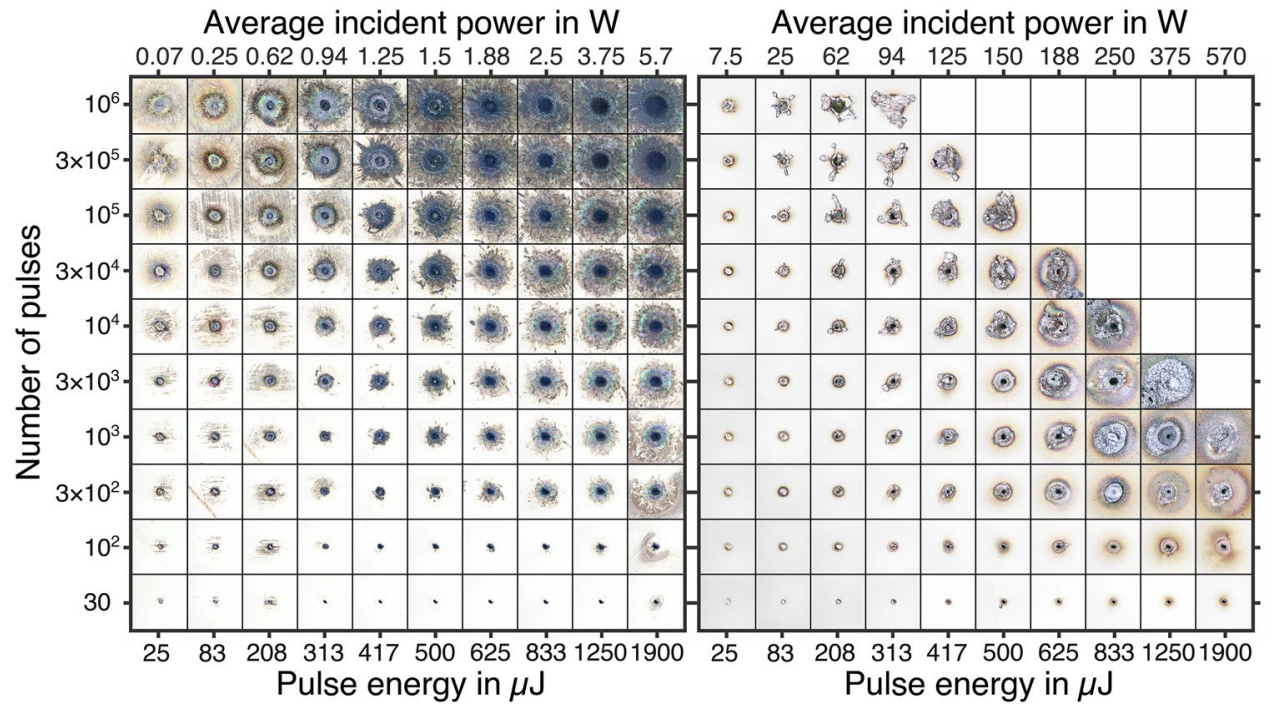


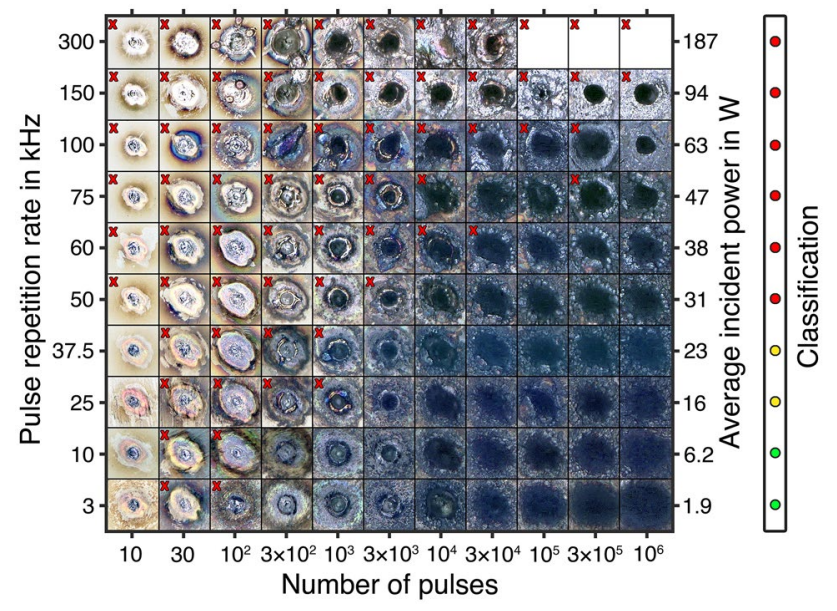

Fig. 4 Illustration of the classification of the experimental results at the example obtained with a beam diameter $d_{0}=60 \mu \mathrm{m}$, a pulse energy of $625 \mu \mathrm{J}$ (irradiated fluence of $22.1 \mathrm{~J} / \mathrm{cm}^{2}$ ). The edge length of the individual square images is $250 \mu \mathrm{m}$. Images marked with a red " $\mathrm{x}$ " exhibit significant amounts of molten material

\section{Discussion}

Both experiments and the theoretical models suggest that using $\mathrm{kW}$ class lasers for the percussion drilling of highquality boreholes is not possible; at least as long as the drilling of single holes is considered. Using advanced process strategies such as energy ramps or helical drilling may alleviate the problem to a limited extent, but cannot fundamentally solve the problem. Hence the results show that processing of singular boreholes is limited to average powers well below $100 \mathrm{~W}$.
As long as individual holes are drilled one by one this finding means that the usable average laser power, and therefore productivity in terms of boreholes drilled per unit of time, is severely limited. This issue can only be overcome by parallelization techniques, i.e. by processing several boreholes in parallel, which may either be realized by spatially distributing the energy instantaneously e.g. by beam splitters (simultaneous parallelization), or by distributing the consecutive pulses to different holes e.g. by a fast scanner [111] (sequential parallelization).

In both cases, the applicable total average power is scaled by the number of holes that are drilled in parallel. For each individual of the many drilled holes, a simultaneous parallelization would mean to horizontally move from right to left in Fig. 5, whereas the sequential parallelization meant moving vertically downwards. Considering the upper abscissa this means that the sequential parallelization has the advantage that deeper holes can be drilled. When the pulse repetition rate exceeds several hundred $\mathrm{kHz}$, the sequential parallelization becomes particularly challenging, as appropriate deflections systems are required to reach deflection speeds in excess of several hundred $\mathrm{rad} / \mathrm{s}$ while maintaining $\mu \mathrm{rad}$ level positioning accuracy in a multi-pass precision drilling process.

Such a processing strategy has been discussed [112] and demonstrated [113], but further system engineering development is required. In contrast, beam splitting systems for simultaneous parallelization are commercially available [114].
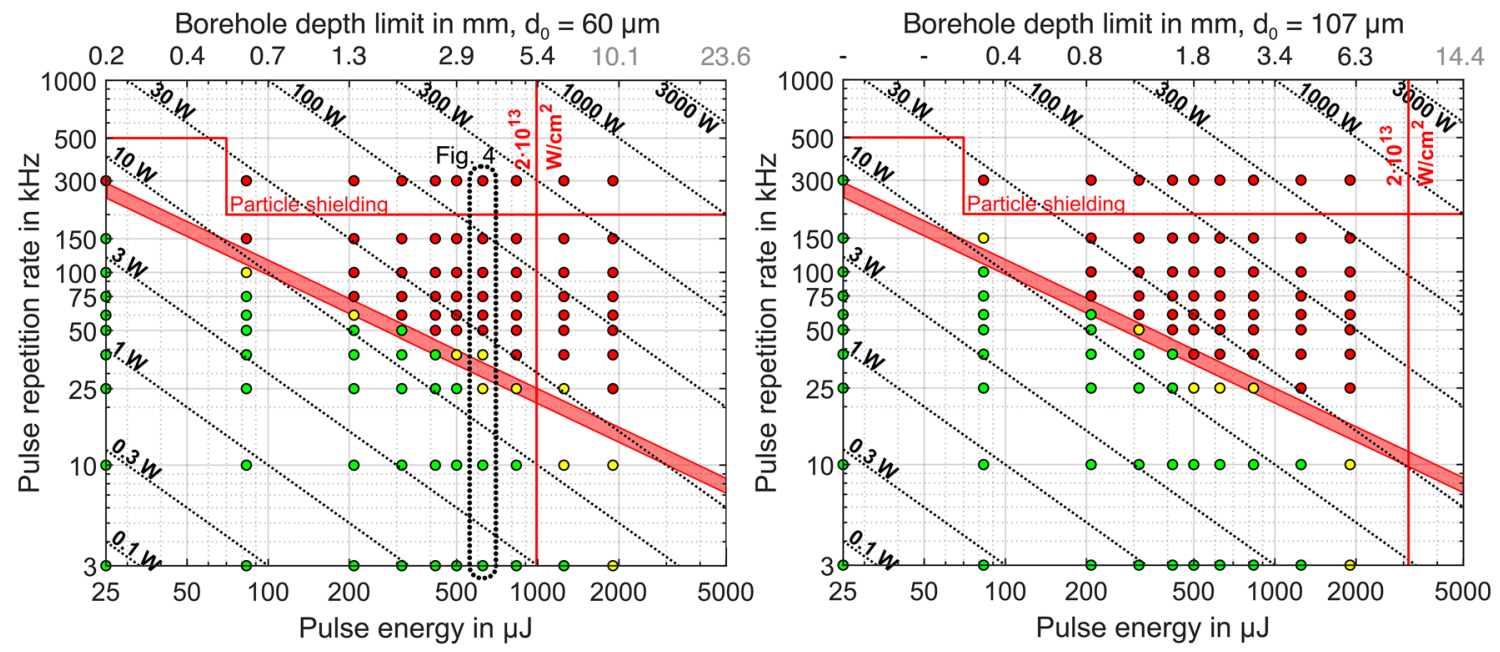

Fig. 5 Classification of the quality of the holes results (colored dots) which were percussion-drilled with a beam diameter of $60 \mu \mathrm{m}$ (left) and $107 \mu \mathrm{m}$ (right). Green: good (no excessive melt), yellow: intermediate, red: poor (due to excessive melt) 


\section{Conclusion}

In view of the current fast advancements of ultrafast lasers and the huge potential, this offers for scaling the productivity of corresponding manufacturing applications, the limits imposed by heat accumulation, particle shielding, and atmosphere breakdown significantly gain importance and need to be considered to plan the processes.

Based on experimental investigations of percussion drilling in AISI 304 stainless steel it was found that the limits imposed by heat accumulation can be well modeled by a simplified model assuming a point source. Combining the limits in one single graph, which takes the general form of Fig. 2, provides useful criteria for the selection of the most suitable processes for percussion drilling.

From this one can conclude that parallelization techniques are mandatory for the economic use of $\mathrm{kW}$ class laser sources in drilling applications. Further research is therefore required for the development of power-capable, precise, and fast scanning and beam multiplexing optical systems.

Funding Open Access funding enabled and organized by Projekt DEAL. The authors received no specific funding for this work.

Data availability The datasets generated during and/or analyzed during the current study are available in the DaRUS repository, [110].

\section{Declarations}

Conflict of interest The authors declare that they have no conflicts of interest.

Open Access This article is licensed under a Creative Commons Attribution 4.0 International License, which permits use, sharing, adaptation, distribution and reproduction in any medium or format, as long as you give appropriate credit to the original author(s) and the source, provide a link to the Creative Commons licence, and indicate if changes were made. The images or other third party material in this article are included in the article's Creative Commons licence, unless indicated otherwise in a credit line to the material. If material is not included in the article's Creative Commons licence and your intended use is not permitted by statutory regulation or exceeds the permitted use, you will need to obtain permission directly from the copyright holder. To view a copy of this licence, visit http://creativecommons.org/licenses/by/4.0/.

\section{References}

1. F. Röser, T. Eidam, J. Rothhardt, O. Schmidt, D.N. Schimpf, J. Limpert, A. Tünnermann, Opt. Lett. 32, 3495 (2007). https://doi. org/10.1364/ol.32.003495

2. F. Röser, D. Schimpf, O. Schmidt, B. Ortaç, K. Rademaker, J. Limpert, A. Tünnermann, Opt. Lett. 32, 2230 (2007). https://doi. org/10.1364/ol.32.002230

3. Y. Zaouter, J. Boullet, E. Mottay, E. Cormier, Opt. Lett. 33, 1527 (2008). https://doi.org/10.1364/ol.33.001527
4. K.-H. Hong, A. Siddiqui, J. Moses, J. Gopinath, J. Hybl, F.O. Ilday, T.Y. Fan, F.X. Kärtner, Opt. Lett. 33, 2473 (2008). https:// doi.org/10.1364/ol.33.002473

5. T. Metzger, A. Schwarz, C.Y. Teisset, D. Sutter, A. Killi, R. Kienberger, F. Krausz, Opt. Lett. 34, 2123 (2009). https://doi.org/10. 1364/OL.34.002123

6. J. Tümmler, R. Jung, H. Stiel, P.V. Nickles, W. Sandner, Opt. Lett. 34, 1378 (2009). https://doi.org/10.1364/ol.34.001378

7. P. Rußbüldt, T. Mans, G. Rotarius, D. Hoffmann, R. Poprawe, T. Eidam, J. Limpert, A. Tünnermann, in Advanced Solid-State Photonics (OSA Washington, D.C., 2009), MF4. https://doi.org/ 10.1364/ASSP.2009.MF4

8. K.-H. Hong, C.-J. Lai, A. Siddiqui, F.X. Kärtner, Opt. Express 17, 16911 (2009). https://doi.org/10.1364/OE.17.016911

9. P. Russbueldt, T. Mans, G. Rotarius, J. Weitenberg, H.D. Hoffmann, R. Poprawe, Opt. Exp. 17, 12230 (2009). https://doi.org/ 10.1364/oe.17.012230

10. K.-H. Hong, J.T. Gopinath, D. Rand, A.M. Siddiqui, S.-W. Huang, E. Li, B.J. Eggleton, J.D. Hybl, T.Y. Fan, F.X. Kärtner, Opt. Lett. 35, 1752 (2010). https://doi.org/10.1364/OL.35.001752

11. D.C. Brown, J.M. Singley, K. Kowalewski, J. Guelzow, V. Vitali, Opt. Exp. 18, 24770 (2010). https://doi.org/10.1364/OE.18. 024770

12. T. Eidam, S. Hanf, E. Seise, T.V. Andersen, T. Gabler, C. Wirth, T. Schreiber, J. Limpert, A. Tünnermann, Opt. Lett. 35, 94 (2010). https://doi.org/10.1364/OL.35.000094

13. P. Russbueldt, T. Mans, J. Weitenberg, H.D. Hoffmann, R. Poprawe, Opt. Lett. 35, 4169 (2010). https://doi.org/10.1364/OL.35. 004169

14. M. Schulz, R. Riedel, A. Willner, T. Mans, C. Schnitzler, P. Russbueldt, J. Dolkemeyer, E. Seise, T. Gottschall, S. Hädrich, S. Duesterer, H. Schlarb, J. Feldhaus, J. Limpert, B. Faatz, A. Tünnermann, J. Rossbach, M. Drescher, F. Tavella, Opt. Lett. 36, 2456 (2011). https://doi.org/10.1364/OL.36.002456

15. J. Rothhardt, T. Eidam, S. Hädrich, F. Jansen, F. Stutzki, T. Gottschall, T.V. Andersen, J. Limpert, A. Tünnermann, Opt. Lett. 36, 316 (2011). https://doi.org/10.1364/OL.36.000316

16. P. Elahi, S. Yılmaz, O. Akçaalan, H. Kalaycıoğlu, B. Oktem, C. Senel, F.Ö. Ilday, K. Eken, Opt. Lett. 37, 3042 (2012). https:// doi.org/10.1364/OL.37.003042

17. H. Lin, J. Li, X. Liang, Opt. Lett. 37, 2634 (2012). https://doi. org/10.1364/OL.37.002634

18. C.J. Saraceno, F. Emaury, O.H. Heckl, C.R.E. Baer, M. Hoffmann, C. Schriber, M. Golling, T. Südmeyer, U. Keller, Opt. Exp. 20, 23535 (2012). https://doi.org/10.1364/OE.20.023535

19. L. Xu, H. Zhang, Y. Mao, Y. Yan, Z. Fan, J. Xin, Appl. Opt. 51, 6669 (2012). https://doi.org/10.1364/AO.51.006669

20. S. Hädrich, A. Klenke, A. Hoffmann, T. Eidam, T. Gottschall, J. Rothhardt, J. Limpert, A. Tünnermann, Opt. Lett. 38, 3866 (2013). https://doi.org/10.1364/OL.38.003866

21. C.Y. Teisset, M. Schultze, R. Bessing, M. Häfner, S. Prinz, D. Sutter, T. Metzger, in Advanced Solid-State Lasers Congress (OSA Washington, D.C., 2013), JTh5A.1. https://doi.org/10. 1364/ASSL.2013.JTh5A.1

22. P. Wan, L.-M. Yang, J. Liu, Opt. Exp. 21, 29854 (2013). https:// doi.org/10.1364/OE.21.029854

23. A. Klenke, S. Breitkopf, M. Kienel, T. Gottschall, T. Eidam, S. Hädrich, J. Rothhardt, J. Limpert, A. Tünnermann, Opt. Lett. 38, 2283 (2013). https://doi.org/10.1364/OL.38.002283

24. J.-P. Negel, A. Voss, M. Abdou Ahmed, D. Bauer, D. Sutter, A. Killi, T. Graf, Opt. Lett. 38, 5442 (2013). https://doi.org/10.1364/ OL.38.005442

25. PicoBlade (Time-Bandwidth Products AG, 2013), https://www. laserfocusworld.com/lasers-sources/article/16561275/picos econd-laser-from-timebandwidth-products-features-pulseondem and. Accessed 4 Nov 2020 
26. T. Mans, J. Dolkemeyer, C. Schnitzler, in International Quantum Electronics Conference (OSA The Optical Society Washington, DC, 2013), p. 1. https://doi.org/10.1109/CLEOE-IQEC.2013. 6801056

27. PX-Series (EdgeWave GmbH, 2013), https://www.edge-wave.de/ web/en/produkte/ultra-short-pulse-systeme/px-serie/. Accessed 4 Nov 2020

28. A. Klenke, S. Hädrich, T. Eidam, J. Rothhardt, M. Kienel, S. Demmler, T. Gottschall, J. Limpert, A. Tünnermann, Opt. Lett. 39, 6875 (2014). https://doi.org/10.1364/OL.39.006875

29. J. Brons, V. Pervak, E. Fedulova, D. Bauer, D. Sutter, V. Kalashnikov, A. Apolonskiy, O. Pronin, F. Krausz, Opt. Lett. 39, 6442 (2014). https://doi.org/10.1364/OL.39.006442

30. T. Mans, R. Graf, J. Dolkemeyer, C. Schnitzler, in Solid State Lasers XXIII: Technology and Devices, ed. by W.A. Clarkson, R.K. Shori (SPIE, 2014), pp. 1-4. https://doi.org/10.1117/12. 2039449

31. TruMicro 5080 (Trumpf Laser- und Systemtechnik GmbH, 2014), https://www.trumpf.com/en_INT/products/laser/short-and-ultra short-pulse-laser/trumicro-series-5000/. Accessed 4 Nov 2020

32. C.J. Saraceno, F. Emaury, C. Schriber, M. Hoffmann, M. Golling, T. Südmeyer, U. Keller, Opt. Lett. 39, 9 (2014). https://doi.org/10.1364/OL.39.000009

33. Z. Zhao, B.M. Dunham, F.W. Wise, J. Opt. Soc. Am. B 31, 33 (2014). https://doi.org/10.1364/JOSAB.31.000033

34. S. Klingebiel, M. Schultze, C.Y. Teisset, R. Bessing, M. Häfner, S. Prinz, M. Gorjan, D. Sutter, K. Michel, H.G. Barros, Z. Major, F. Krausz, T. Metzger, in 2015 Conference on Lasers and Electro-Optics (CLEO) (IEEE Piscataway, NJ, 2015), STu4O.2. https://doi.org/10.1364/CLEO_SI.2015.STu4O.2

35. J.-P. Negel, A. Loescher, A. Voss, D. Bauer, D. Sutter, A. Killi, M.A. Ahmed, T. Graf, Opt. Exp. 23, 21064 (2015). https://doi. org/10.1364/OE.23.021064

36. M. Kienel, M. Müller, A. Klenke, J. Limpert, A. Tünnermann, Opt. Lett. 41, 3343 (2016). https://doi.org/10.1364/OL.41. 003343

37. M. Ueffing, R. Lange, T. Pleyer, V. Pervak, T. Metzger, D. Sutter, Z. Major, T. Nubbemeyer, F. Krausz, Opt. Lett. 41, 3840 (2016). https://doi.org/10.1364/OL.41.003840

38. M. Müller, M. Kienel, A. Klenke, T. Gottschall, E. Shestaev, M. Plötner, J. Limpert, A. Tünnermann, Opt. Lett. 41, 3439 (2016). https://doi.org/10.1364/OL.41.003439

39. Tangor 100 (Amplitude Laser, 2016), https://amplitude-laser. com/products/femtosecond-lasers/tangor/. Accessed 4 Nov 2020

40. FX-Series (EdgeWave GmbH, 2016), https://www.edge-wave.de/ web/en/produkte/ultra-short-pulse-systeme/fx-serie/. Accessed 4 Nov 2020

41. C. Baumgarten, M. Pedicone, H. Bravo, H. Wang, L. Yin, C.S. Menoni, J.J. Rocca, B.A. Reagan, Opt. Lett. 41, 3339 (2016). https://doi.org/10.1364/OL.41.003339

42. H. Fattahi, A. Alismail, H. Wang, J. Brons, O. Pronin, T. Buberl, L. Vámos, G. Arisholm, A.M. Azzeer, F. Krausz, Opt. Lett. 41, 1126 (2016). https://doi.org/10.1364/OL.41.001126

43. J.-P. Negel, A. Loescher, D. Bauer, D. Sutter, A. Killi, M.A. Ahmed, T. Graf, in Applications of Lasers for Sensing and Free Space Communications (OSA-The Optical Society Washington, D.C., USA, 2016), ATu4A.5. https://doi.org/10.1364/ASSL. 2016.ATu4A.5

44. AMPHOS 400 (AMPHOS GmbH, 2016), https://www.amphos. de/products/amphos-400/. Accessed 4 Nov 2020

45. Polaris i200 (AMS Technologies AG, 2016), http://www.amste chnologies.com/de/fiberlasersystems/view/polaris-i200-infrared-pico-second-lasers-1064-nm/. Accessed 5 Nov 2020

46. HyperRapid NX (Coherent, Inc., 2016), https://www.coherent. com/lasers/laser/hyper-rapid-nx. Accessed 5 Nov 2020
47. PicoBlade 2 (Lumentum Operations LLC, 2016), https://www. lumentum.com/en/products/laser-ultrafast-industrial-picoblade2. Accessed 4 Nov 2020

48. T. Sartorius, P. Russbueldt, P. Bauer, D. Sutter, D. Hoffmann, in Solid State Lasers XXV: Technology and Devices, ed. by W.A. Clarkson, R.K. Shori (SPIE, 2016), pp. 9726-9742

49. M. Mueller, A. Klenke, H. Stark, J. Buldt, T. Gottschall, J. Limpert, A. Tünnermann, in Laser Applications Conference (OSAThe Optical Society Washington, D.C., USA, 2017), AW4A.3. https://doi.org/10.1364/ASSL.2017.AW4A.3

50. F.X. Morrissey, T.Y. Fan, D.E. Miller, D. Rand, Opt. Lett. 42, 707 (2017). https://doi.org/10.1364/OL.42.000707

51. T. Nubbemeyer, M. Kaumanns, M. Ueffing, M. Gorjan, A. Alismail, H. Fattahi, J. Brons, O. Pronin, H.G. Barros, Z. Major, T. Metzger, D. Sutter, F. Krausz, Opt. Lett. 42, 1381 (2017). https:// doi.org/10.1364/OL.42.001381

52. B.E. Schmidt, A. Hage, T. Mans, F. Légaré, H.J. Wörner, Opt. Exp. 25, 17549 (2017). https://doi.org/10.1364/OE.25.017549

53. C. Wandt, S. Klingebiel, M. Schultze, S. Prinz, C.Y. Teisset, S. Stark, C. Grebing, M. Häfner, R. Bessing, T. Herzig, A. Budnicki, D. Sutter, K. Michel, T. Nubbemeyer, F. Krausz, T. Metzger, in 2017 Conference on Lasers and Electro-Optics (CLEO) (IEEE Piscataway, NJ, 2017), STh1L.1. https://doi.org/ 10.1364/CLEO_SI.2017.STh1L.1

54. M. Mueller, A. Klenke, A. Steinkopff, H. Stark, A. Tünnermann, J. Limpert, Opt. Lett. 43, 6037 (2018). https://doi.org/10.1364/ OL.43.006037

55. AMPHOS 400 Upgrade (AMPHOS GmbH, 2018), https://www. amphos.de/products/amphos-400/. Accessed 4 Nov 2020

56. Atlantic 80 (EKSPLA, 2018), https://ekspla.com/product/atlan tic-series-industrial-picosecond-diode-pumped-laser/\#tab3. Accessed 5 Nov 2020

57. H. Stark, J. Buldt, M. Müller, A. Klenke, A. Tünnermann, J. Limpert, Opt. Lett. 44, 5529 (2019). https://doi.org/10.1364/OL.44.005529

58. P. Russbueldt, J. Weitenberg, J. Schulte, R. Meyer, C. Meinhardt, H.D. Hoffmann, R. Poprawe, Opt. Lett. 44, 5222 (2019). https:// doi.org/10.1364/OL.44.005222

59. Tangor 300 (Amplitude Laser, 2019), https://amplitude-laser. com/products/femtosecond-lasers/tangor/. Accessed 4 Nov 2020

60. P. Krötz, C. Wandt, C. Grebing, C. Herkommer, R. Jung, S. Klingebiel, S. Prinz, C.Y. Teisset, K. Michel, T. Metzger, in Laser Applications Conference (OSA-The Optical Society Washington, D.C., USA, 2019), ATh1A.8. https://doi.org/10. 1364/ASSL.2019.ATh1A.8

61. Dira 750-5 (TRUMPF Scientific Lasers GmbH + Co. KG, 2019), https://www.trumpf-scientific-lasers.com/products/dira-series/. Accessed 4 Nov 2020

62. Amphos 5206 (AMPHOS GmbH, 2019), https://www.amphos. de/products/amphos5000/. Accessed 4 Nov 2020

63. mJ-CLASS (Active Fiber Systems GmbH, 2019), https://www. afs-jena.de/index.php/products/\#mJkW. Accessed 4 Nov 2020

64. M. Müller, C. Aleshire, A. Klenke, E. Haddad, F. Légaré, A. Tünnermann, J. Limpert, Opt. Lett. 45, 3083 (2020). https://doi. org/10.1364/OL.392843

65. C. Herkommer, P. Krötz, R. Jung, S. Klingebiel, C. Wandt, R. Bessing, P. Walch, T. Produit, K. Michel, D. Bauer, R. Kienberger, T. Metzger, Opt. Exp. 28, 30164 (2020). https://doi.org/ 10.1364/OE.404185

66. T. Dietz, M. Jenne, D. Bauer, M. Scharun, D. Sutter, A. Killi, Opt. Exp. 28, 11415 (2020). https://doi.org/10.1364/OE.383926

67. Advanced Photon Sources CAPS-HPE (Fraunhofer, 2020), https://www.caps.fraunhofer.de/en/news/press-release-2019-515.html. Accessed 5 Nov 2020

68. C. Röcker, A. Loescher, F. Bienert, P. Villeval, D. Lupinski, D. Bauer, A. Killi, T. Graf, M. Abdou Ahmed, Opt. Lett. 45, 5522 (2020). https://doi.org/10.1364/OL.403781 
69. Advanced Photon Sources CAPS - LPE (Fraunhofer, 2020), https://www.caps.fraunhofer.de/en/news/press-release-2019-515.html. Accessed 5 Nov 2020

70. PicoBlade 3 (Lumentum Operations LLC, 2020), https://www. lumentum.com/en/products/laser-ultrafast-industrial-picoblade3. Accessed 4 Nov 2020

71. C. Freitag, M. Wiedenmann, J.-P. Negel, A. Loescher, V. Onuseit, R. Weber, M. Abdou Ahmed, T. Graf, Appl. Phys. A 119, 1237 (2015). https://doi.org/10.1007/s00339-015-9159-3

72. S. Faas, U. Bielke, R. Weber, T. Graf, Appl. Phys. A 124, 1 (2018). https://doi.org/10.1007/s00339-018-2040-4

73. D. Holder, R. Weber, C. Röcker, G. Kunz, D. Bruneel, M. Delaigue, T. Graf, M.A. Ahmed, Opt. Lett. 46, 384 (2021). https://doi.org/10.1364/OL.411412

74. S. Nolte, C. Momma, H. Jacobs, A. Tünnermann, B.N. Chichkov, B. Wellegehausen, H. Welling, J. Opt. Soc. Am. B 14, 2716 (1997). https://doi.org/10.1364/JOSAB.14.002716

75. R. Weber, T. Graf, P. Berger, V. Onuseit, M. Wiedenmann, C. Freitag, A. Feuer, Opt. Exp. 22, 11312 (2014). https://doi.org/ 10.1364/OE.22.011312

76. A. Ancona, F. Röser, K. Rademaker, J. Limpert, S. Nolte, A. Tünnermann, Opt. Exp. 16, 8958 (2008). https://doi.org/10.1364/ oe. 16.008958

77. J. Finger, M. Reininghaus, Opt. Exp. 22, 18790 (2014). https:// doi.org/10.1364/OE.22.018790

78. D.J. Förster, R. Weber, T. Graf, in Proceedings of LPM2017The 18th International Symposium on Laser Precision Microfabrication, ed. by Japan Laser Processing Society (JLPS) (2017), pp. 1-4

79. R. Weber, T. Graf, C. Freitag, A. Feuer, T. Kononenko, V.I. Konov, Opt. Exp. 25, 3966 (2017). https://doi.org/10.1364/OE. 25.003966

80. F. Bauer, A. Michalowski, T. Kiedrowski, S. Nolte, Opt. Exp. 23, 1035 (2015). https://doi.org/10.1364/OE.23.001035

81. D. Metzner, P. Lickschat, S. Weißmantel, Appl. Phys. A 126 (2020). https://doi.org/10.1007/s00339-019-3203-7

82. I. Mingareev, Ultrafast Dynamics of Melting and Ablation at Large Laser Intensities (Cuvillier Verlag, Göttingen, 2009)

83. H.S. Carslaw, J.C. Jaeger, Conduction of Heat in Solids (Oxford University Press, Oxford, 1959)

84. D. Breitling, A. Ruf, F. Dausinger, in Photon Processing in Microelectronics and Photonics III, ed. by P.R. Herman, J. Fieret, A. Pique, T. Okada, F.G. Bachmann, W. Hoving, K. Washio, X. Xu, J.J. Dubowski, D.B. Geohegan, F. Traeger (SPIE, 2004), pp. 49-63. https://doi.org/10.1117/12.541434

85. D. Breitling, A. Ruf, P.W. Berger, F.H. Dausinger, S.M. Klimentov, P.A. Pivovarov, T.V. Kononenko, V.I. Konov, in Laser Processing of Advanced Materials and Laser Microtechnologies, ed. by F.H. Dausinger, V.I. Konov, V.Y. Baranov, V.Y. Panchenko (SPIE, 2002), pp. 24-33. https://doi.org/10.1117/12.513766

86. D. Breitling, S. Klimentov, F. Dausinger, in Femtosecond technology for technical and medical applications, ed. by $\mathrm{F}$. Dausinger, F. Lichtner, H. Lubatschowski (Springer Berlin, 2004), pp. 75-91. https://doi.org/10.1007/978-3-540-39848-6_6

87. J.K. Koga, K. Moribayashi, Y. Fukuda, S.V. Bulanov, A. Sagisaka, K. Ogura, H. Daido, M. Yamagiwa, T. Kimura, T. Fujikawa, M. Ebina, K. Akihama, J. Phys. D Appl. Phys. 43, 25204 (2010). https://doi.org/10.1088/0022-3727/43/2/025204

88. A. Schmitt-Sody, H.G. Kurz, L. Bergé, S. Skupin, P. Polynkin, New J. Phys. 18, 93005 (2016). https://doi.org/10.1088/13672630/18/9/093005

89. S.M. Klimentov, T.V. Kononenko, P.A. Pivovarov, S.V. Garnov, V.I. Konov, D. Breitling, F.H. Dausinger, in Laser Processing of Advanced Materials and Laser Microtechnologies, ed. by F.H. Dausinger, V.I. Konov, V.Y. Baranov, V.Y. Panchenko (SPIE, 2002), p. 77. https://doi.org/10.1117/12.513819
90. P. Agostini, G. Barjot, J. Bonnal, G. Mainfray, C. Manus, J. Morellec, IEEE J. Quantum Electron. 4, 667 (1968). https://doi. org/10.1109/JQE.1968.1074955

91. A.J. Alcock, K. Kato, M.C. Richardson, Opt. Commun. 6, 342 (1972). https://doi.org/10.1016/0030-4018(72)90151-4

92. R.J. Dewhurst, J. Phys. D Appl. Phys. 10, 283 (1977). https://doi. org/10.1088/0022-3727/10/3/008

93. C.L.M. Ireland, C.G. Morgan, J. Phys. D Appl. Phys. 6, 720 (1973). https://doi.org/10.1088/0022-3727/6/6/314

94. G.V. Ostrovskaya, A.N. Zaŭdel', Sov. Phys. Usp. 16, 834 (1974). https://doi.org/10.1070/PU1974v016n06ABEH004094

95. E.W. van Stryland, M.J. Soileau, A.L. Smirl, W.E. Williams, in Laser Induced Damage in Optical Materials, ed. by H.E. Bennett (American Society for Testing \& Materials West Conshohocken, 1981), pp. 375-384. https://doi.org/10.1520/STP37029S

96. M.H. Niemz, Appl. Phys. Lett. 66, 1181 (1995). https://doi.org/ 10.1063/1.113850

97. W.E. Williams, M.J. Soileau, E.W. van Stryland, Appl. Phys. Lett. 43, 352 (1983). https://doi.org/10.1063/1.94334

98. R. Tambay, D.V.S. Muthu, V. Kumar, R.K. Thareja, Pramana J. Phys. 37, 163 (1991). https://doi.org/10.1007/BF02875303

99. M. Thiyagarajan, S. Thompson, J. Appl. Phys. 111, 1 (2012). https://doi.org/10.1063/1.3699368

100. Y. Wang, X. Wang, N. Zhang, H. Zhai, X. Zhu, in High-Power Lasers and Applications III, ed. by D. Fan, K. Ueda, J. Lee (SPIE, 2004), pp. 105-111. https://doi.org/10.1117/12.575635

101. R. Paschotta, Encyclopedia of Laser Physics and Technology (Wiley-VCH, Weinheim, 2008)

102. J. König, S. Nolte, A. Tünnermann, Opt. Exp. 13, 10597 (2005). https://doi.org/10.1364/opex.13.010597

103. S. Döring, T. Ullsperger, F. Heisler, S. Richter, A. Tünnermann, S. Nolte, Phys. Proc. 41, 431 (2013). https://doi.org/10.1016/j. phpro.2013.03.099

104. A. Ancona, S. Döring, C. Jauregui, F. Röser, J. Limpert, S. Nolte, A. Tünnermann, Opt. Lett. 34, 3304 (2009). https://doi.org/10. 1364/OL.34.003304

105. D. Holder, R. Weber, T. Graf, V. Onuseit, D. Brinkmeier, D.J. Förster, A. Feuer, Appl. Phys. A 127, 1 (2021). https://doi.org/ 10.1007/s00339-021-04455-3

106. A. Gouffé, Rev. Opt. 24, 1 (1945)

107. A. Gouffé, Aperture Corrections of Artificial Black Bodies with Consideration of Multiple Internal Diffusions (1960)

108. H. Hügel, T. Graf, Laser in der Fertigung: Strahlquellen, Systeme, Fertigungsverfahren: Strahlquellen, Systeme, Fertigungsverfahren (Vieweg+Teubner, Wiesbaden, 2014)

109. J.M. Liu, Opt. Lett. 7, 196 (1982). https://doi.org/10.1364/ol.7. 000196

110. USP percussion drilling in steel borehole inlet image dataset (USPpdisbiims-v1) (D. Brinkmeier), https://doi.org/10.18419/darus-1831

111. B. Neuenschwander, B. Jaeggi, M. Schmid, G. Hennig, Phys. Proc. 56, 1047 (2014). https://doi.org/10.1016/j.phpro.2014.08.017

112. R. De Loor, L. Penning, R. Slagle, LTJ 11, 32 (2014). https://doi. org/10.1002/latj.201400033

113. R. Patwa, H. Herfurth, G. Mueller, K. Bui, in Laser Material Processing for Solar Energy Devices II, ed. by E.W. Reutzel (SPIE, 2013), 88260G. https://doi.org/10.1117/12.2026539

114. MultiBeam Scanner MBS G3 (Pulsar Photonics GmbH, 2014), https://www.pulsar-photonics.de/en/system-technology/multi beam-scanner-mbs/. Accessed 26 Aug 2019

Publisher's Note Springer Nature remains neutral with regard to jurisdictional claims in published maps and institutional affiliations. 